in vivo $32: 1457-1462(2018)$

doi:10.21873/invivo.11399

\title{
Impact of FDG-PET on the Detection of Patients with Lung Cancer at High Risk for ILD
}

\author{
PAUL FLECHSIG ${ }^{1,2,3}$, OLENA HURAL ${ }^{3}$, MICHAEL KREUTER ${ }^{2,4}$, MARTIN EICHHORN ${ }^{2,5}$, \\ GUDULA HEUßEL ${ }^{2,3,5}$, CHRISTOS SACHPEKIDIS ${ }^{1,6}$, HANS-ULRICH KAUCZOR $^{2,7}$, \\ UWE HABERKORN $^{1,2,6}$, CLAUS PETER HEUSSEL ${ }^{2,3}$ and MONIKA EICHINGER ${ }^{2,3}$ \\ Departments of ${ }^{1}$ Nuclear Medicine, and ${ }^{7}$ Diagnostic and Interventional Radiology, \\ University Hospital Heidelberg, Heidelberg, Germany; \\ ${ }^{2}$ Translational Lung Research Center Heidelberg, \\ Member of the German Center for Lung Research DZL, Heidelberg, Germany; \\ ${ }^{3}$ Division of Diagnostic and Interventional Radiology with Nuclear Medicine, \\ ${ }^{4}$ Centre for Interstitial and Rare Lung Diseases, Pneumology and Respiratory Critical Care Medicine, and \\ ${ }^{5}$ Department of Thoracic Surgery, Thorax Clinic, University of Heidelberg, Heidelberg, Germany; \\ ${ }^{6}$ Clinical Cooperation Unit, Department of Nuclear Medicine, \\ German Cancer Research Center (DKFZ), Heidelberg, Germany
}

\begin{abstract}
Background/Aim: Idiopathic pulmonary fibrosis IPF is a type of interstitial lung disease (ILD) with poor prognosis. Lung cancer $(L C)$ is a frequent complication in $I P F$, where all therapeutic options are potential triggers for acute exacerbation of IPF. Patients and Methods: Patients with 2-deoxy-2-fluoro-D-glucose-positron emission tomography/computer tomography (FDG-PET/CT) results before lobectomy for $L C$ with and without $(n=10$ each) signs of ILD in initial imaging and after-care CT were retrospectively analyzed. FDG uptake was calculated as the maximum standardized uptake value $\left(S U V_{\max }\right)$ in the lung periphery divided by the $S U V_{\text {max }}$ of the mediastinal blood pool $\left(r S U V_{\text {max }}\right)$. Regional increase of fibrosis and groundglass features in lobe-based CT analysis was used as standard reference. Results: Patients with LC with ILD presented a significantly higher $r S U V_{\max }$ of 0.57 compared to patients without ILD with $r S U V_{\max } 0.47(p<0.001)$. Conclusion: $r S U V_{\max }$ seems to be a valuable imaging surrogate in predicting patients with LC with increased risk for progressive ILD associated with thoracic surgery.
\end{abstract}

This article is freely accessible online.

Correspondence to: Dr. Paul Flechsig, Department of Nuclear Medicine, University Hospital Heidelberg, INF 400, 69120 Heidelberg, Germany. Tel: +49 6221567733, e-mail: paul.flechsig@ med.uni-heidelberg.de

Key Words: Lung cancer, staging, interstitial lung disease, FDG/PET-CT.
Interstitial lung diseases (ILD) are associated with an increased mortality (1-3). Idiopathic pulmonary fibrosis (IPF), in particular, has an increasing incidence, and can be classified as a life-threatening condition, associated with a median survival of 3-4 years, comparable to that of patients suffering from malignant diseases (4). As reported in a study evaluating more than 9,000 patients with IPF in the US, comorbidities in IPF are frequent and associated with an increased mortality (4, 5). Moreover, an increased risk for the development of lung cancer (LC) was shown in a recent study evaluating comorbidities of more than 5,000 patients with IPF in Japan, with a prevalence of $3.7 \%$ for those hospitalized with IPF (6). Similarly, an increased incidence of LC has been highlighted in patients with IPF in two studies from the UK $(7,8)$.

Due to the increased risk for LC in patients with ILD, therapeutic stratifications are often difficult (9). In clinical routine, high-resolution computed tomography (HRCT) is essential for the diagnosis of ILD, including IPF (10). The role of 2-deoxy-2-[ $\left[{ }^{18} \mathrm{~F}\right]$ fluoro-D-glucose positron-emission tomography/CT $\left({ }^{18} \mathrm{~F}-\mathrm{FDG}-\mathrm{PET} / \mathrm{CT}\right)$ in ILD has not been elucidated. Nevertheless, several studies have documented an increased FDG uptake in patients with IPF undergoing PET/CT (10-13). In particular, the observed increase of standardized uptake value $\left(\mathrm{SUV}_{\max }\right)$ has been shown to be useful for the prediction of functional improvement under drug treatment (13). Interestingly, an increased FDG uptake was not only found in areas of destroyed lung architecture, but also in areas of the lung with normal morphological appearance (10). Moreover, an increased retention index value (RI-SUV) in dual-time-point ${ }^{18}$ F-FDG-PET was described as an independent prognostic factor for shorter progression-free survival (12). 
${ }^{18}$ F-FDG-PET/CT serves as a routine staging methodology in patients with LC (14). Since surgery for LC is an established risk factor for exacerbation of pre-existing IPF (15-19), associated with significant disease progression and a high mortality, individual risk assessment might be improved if ${ }^{18}$ F-FDG-PET/CT could also help to predict this dreadful complication. In order to further exhaust the clinical information derived from routinely performed pre-operative ${ }^{18}$ F-FDG-PET/CT examinations in patients with LC, the impact of FDG uptake in peripheral lung parenchyma on the progression of pre-existing ILD was evaluated. The hypothesis of this study was that increased FDG uptake in peripheral lung tissue in PET/CT might be used as an imaging surrogate for the differentiation between patients with surgery-triggered progression of pre-existing ILD, and patients that do not have an increased risk for ILD.

\section{Materials and Methods}

Study design and patients. Patient selection was performed using a database of more than 200 patients suffering from non-small cell LC with available pre-operative ${ }^{18} \mathrm{~F}-\mathrm{FDG}-\mathrm{PET} / \mathrm{CT}$ as well as postoperative CT. Patients with prior radiation or chemotherapy were excluded from the analysis, as well as patients with preoperative CT scans with severe artefacts due to metal implants or breathing artefacts. Finally, 20 patients $(50 \%$ male; median age $=67$ years, range $=55-85$ years) were analyzed retrospectively using a single-center design, and two groups were formed and compared: one group with 10 consecutive patients with pre-existing and progressive ILD by postoperative imaging (ILD group), and a second group with 10 patients with no signs of ILD in initial and follow-up imaging (control group).

Regional radiological signs for ILD as visually detectable at initial and follow-up CT were used as gold standard. All ${ }^{18} \mathrm{~F}-\mathrm{FDG}-\mathrm{PET} / \mathrm{CT}$ examinations were performed according to the clinical schedule within 2 weeks prior to surgery. FDG uptake was measured once prior to surgery in the preoperative ${ }^{18} \mathrm{~F}-\mathrm{FDG}-\mathrm{PET} / \mathrm{CT}$ examination in all patients. Absence and presence of ILD was quantified accordingly in pre-and postoperative follow-up CT examinations. Up to three postoperative CT scans were reviewed per patient, covering a time frame after surgery of a median of 408 (range $=159-716$ ) days in the ILD group and 320 (range=81-1159) days in the control group. The study was approved by the Institutional Review Board (080/2006) and conducted according to the guidelines of the Institutional Review Board and to good clinical practice according to the ethical principles that have their origin in the Declaration of Helsinki. In this retrospective analysis, the requirement for informed consent was waived by the Institutional Review Board.

Imaging procedures. ${ }^{18} \mathrm{~F}-\mathrm{FDG}$-PET/CT: ${ }^{18} \mathrm{~F}-\mathrm{FDG}-\mathrm{PET} / \mathrm{CT}$ examinations were performed as part of preoperative staging according to clinical routine using a Biograph 6 PET/CT Scanner (Siemens, Erlangen, Germany). Imaging sequences and protocols were described earlier in detail $(20,21)$ : after fasting for at least 6 hours (blood glucose level below $150 \mathrm{mg} / \mathrm{dl}$ ), $4 \mathrm{MBq} / \mathrm{kg}$ body weight of ${ }^{18} \mathrm{~F}$-FDG were administered intravenously $60 \pm 5$ minutes before the FDG-PET/CT scan. The following examination protocols and reconstruction parameters were applied: slice thickness/reconstruction increment of 5.0/2.5 mm, standard soft-tissue reconstruction kernel B30 and B70 high-resolution. Static emission scans (eight bed positions, 4 minutes each) from the vertex to the proximal legs were performed with correction for dead time, scatter and decay. Nonenhanced low-dose CT was acquired for reasons of attenuation correction. For iterative image reconstructions, ordered subset expectation maximization (OSEM) algorithm was applied (four iterations, eight subsets and Gaussian filtering), resulting in an inplane spatial resolution of $5 \mathrm{~mm}$ at full-width half-maximum. In cases where no preoperative $\mathrm{CT}$ was available, fibrotic remodeling was examined on the basis of non-enhanced CT scans that accompanied the preoperative ${ }^{18} \mathrm{~F}-\mathrm{FDG}-\mathrm{PET} / \mathrm{CT}$ scan. CT parameters were adjusted according to patient's weight (120 keV, 40-150 mAs) using a section width of $5 \mathrm{~mm}$ and pitch of $0.8^{\circ}$.

Pre-and post-operative CT: According to clinical routine, eight out of 20 patients underwent initial CT for preoperative staging as inspiratory CT, which was technically identical to the scans that were performed postoperatively. In another 12 patients, initial quantification of fibrotic lung disease was performed using the CT component of the above mentioned ${ }^{18} \mathrm{~F}-\mathrm{FDG}-\mathrm{PET} / \mathrm{CT}$ examination in respiratory center position, since other CT scans were outdated, impeded by artefacts, or performed with very thick sections. Preoperative CT scan was taken at a median of 24 (range=0-49) days prior surgery. The distribution of the above-mentioned issues was identical in both groups. Concerning postoperative follow-up assessments of ILD, all examinations were performed as part of routinely performed oncological aftercare as contrast-enhanced CT examinations using an AS64 CT scanner (Siemens) with a biphasic intravenous injection of $40 \mathrm{ml}$ at $2 \mathrm{ml} / \mathrm{s}$ contrast agent (Ultravist 300; Bayer Vital, Leverkusen, Germany) followed by a second bolus of $60 \mathrm{ml}$ at $2 \mathrm{ml} / \mathrm{s}$ after $40 \mathrm{~s}$ with $30 \mathrm{ml}$ of saline flush covering from below the adrenal glands through the lung apices. CT data sets were reconstructed at a slice thickness of 3.0 $\mathrm{mm}$ using a $2.5-\mathrm{mm}$ increment with an $\mathrm{I} 30$ standard soft-tissue kernel and an I70 high-resolution kernel.

Image analysis and quantification. As described earlier (22), quantification of $\mathrm{SUV}_{\max }$ was examined in reconstructed noncontrast-enhanced CT and PET images that were displayed on a dedicated workstation equipped with Syngo software (Siemens). Clinical image interpretation was carried out by one Board-approved nuclear medicine physician and one Board-approved radiologist (23$25)$. Both readers were blinded to clinical information. For the analysis of the PET component, a semi-automatic spherical volume of interest (VOI) was drawn on each of the six lung lobes with lingula serving as the left equivalent to the middle lobe. When necessary, borders of each VOI were adjusted manually in all three dimensions in order to exclude the adjacent chest wall, tumor tissue or surrounding vessels. Moreover, a VOI in the descending aorta was drawn to measure $\mathrm{SUV}_{\max }$ of the blood pool (BP). FDG uptake was evaluated using the parameter $\mathrm{SUV}_{\max }$ calculated 60 minutes after tracer injection. The relative $\mathrm{SUV}_{\max }\left(\mathrm{rSUV}_{\max }\right)$ was calculated as the $\mathrm{SUV}_{\max }$ in the lung periphery divided by the $\mathrm{SUV}_{\max }$ of the mediastinal BP, which was measured in the ascending aorta.

The amount of ILD was estimated visually as the percentage of tissue within the respective lobe affected by fibrosis and groundglass attenuation, according to a recent publication (26). According to the underlying disease and ongoing treatment, the change in follow-up CT was only available for non-resected $(n=21)$, nonirradiated $(n=2)$, nor otherwise affected lobes (i.e. compression atelectasis due to effusion, $n=2$ ). 

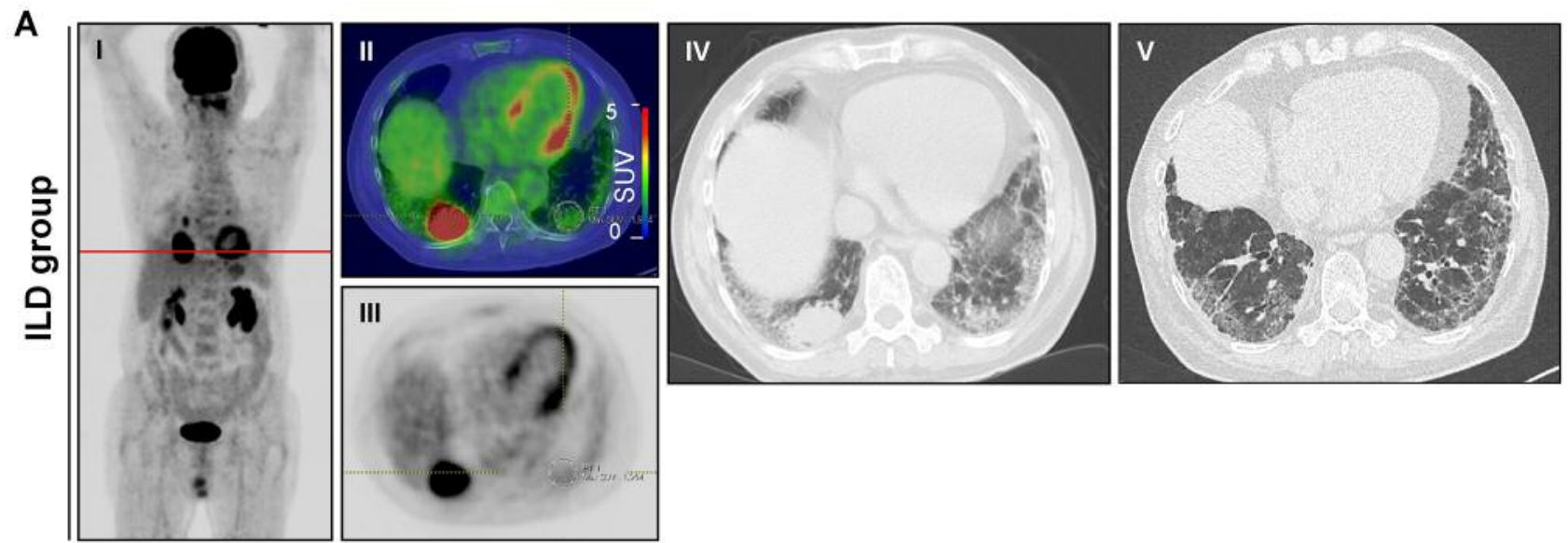

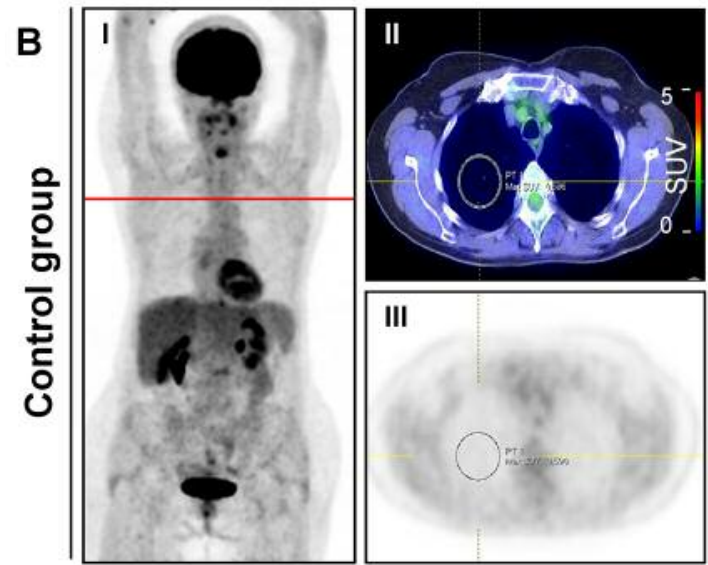

${ }^{18} \mathrm{~F}$-FDG-PET/CT
Initial CT

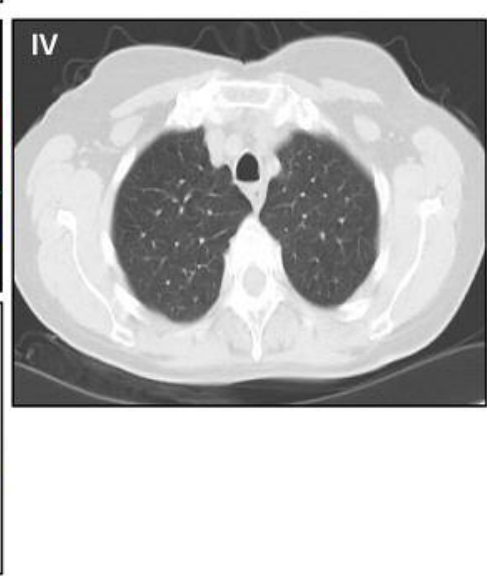

\section{Follow-up CT}

Figure 1. Initial 2-deoxy-2-[ ${ }^{18}$ F]fluoro-D-glucose-positron-emission tomography/computer tomography (18 F-FDG-PET/CT), initial and follow-up CT. A: Patient with interstitial lung disease (ILD; ILD group). B: Patient with no signs of ILD (control group). I: 18 F-FDG-PET/CT with multiintensity projection of PET (red line indicating slices for axial images). II: Fused axial PET/CT, orange circle indicates region of interest (ROI) for maximum standardized uptake value $\left(S U V_{\text {max }}\right)$ measurement. III: Axial views of PET, orange circle indicates ROI for SUV $V_{\text {max }}$ measurement. IV: Axial views of initial CT as part of integrated ${ }^{18}$ F-FDG-PET/CT. V: Axial views of postoperative contrast-enhanced follow-up CT.

Statistical analysis. Statistical analysis was based on a lobe-based analysis using SigmaPlot (Systat Software GmbH, Erkrath, North Rhine-Westphalia, Germany). Median and quartile values for $\mathrm{SUV}_{\max }$ with $95 \%$ confidence interval were calculated and illustrated in box-and-whisker plots using the results for fibrotic progression from follow-up CT examinations as standard of reference.

For comparison of uptake values, the non-parametric Wilcoxon signed-rank test for two paired samples was used. The significance level used was $p \leq 0.05$ (two-tailed). Sensitivities and specificities of all measured markers were investigated using receiver operating characteristic (ROC) analysis and the area under the ROC curve (AUC).

\section{Results}

FDG uptake in preoperative ${ }^{18} F-F D G-P E T / C T$. For the semi-automated analysis of FDG uptake of peripheral lung parenchyma in the fused images of ${ }^{18}$ F-FDG-PET, less than 10 minutes of additional reading time was necessary for each patient (Figure 1). Semi-automated quantification of fibrotic remodeling in the CT component of integrated ${ }^{18} \mathrm{~F}-\mathrm{FDG}-$ $\mathrm{PET} / \mathrm{CT}$ or CT resulted in an extra reading time of not more than 10 minutes for each patient.

Regarding FDG uptake, $\mathrm{rSUV}_{\max }$ in peripheral lung parenchyma was significantly higher in the VOIs of patients suffering from ILD compared to the control group. In detail, patients with ILD presented a median $\mathrm{rSUV}_{\max }$ of $0.57(0.27$ 1.38) compared to a $0.47(0.22-1.07)$ in the control group $(p<0.001$; Figure 2). Concerning the analysis of absolute $\mathrm{SUV}_{\text {max }}$, patients with ILD presented a median $\mathrm{SUV}_{\text {max }}$ of 1.15 (0.47-2.47) compared to $1.00(0.55-2.01)$ of the control group, which was not statistically significantly different $(p=0.19)$.

ROC analyses and AUC. In order to compare the impact of $\mathrm{SUV}_{\text {max }}$ and $\mathrm{rSUV}_{\text {max }}$ for the prediction of progressive ILD, 


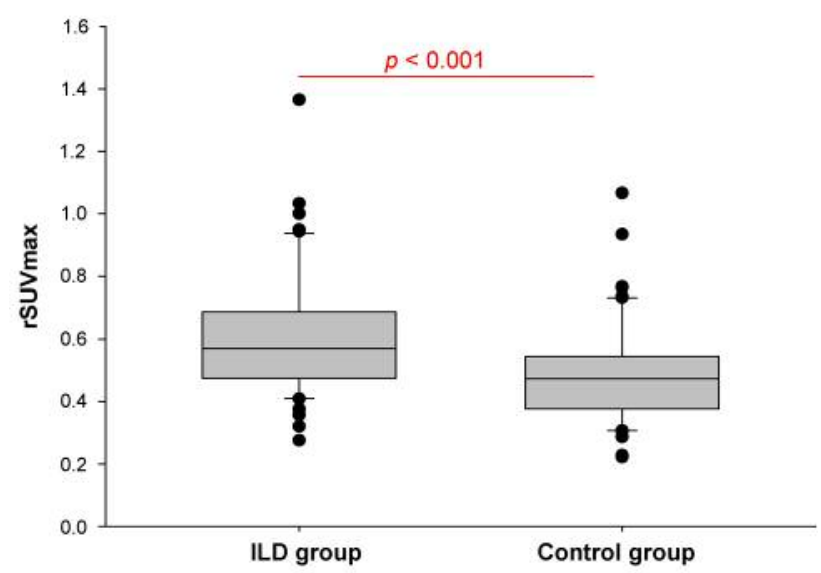

Figure 2. Box plots of relative maximum standardized uptake value $\left(r S U V_{\max }\right)$ in peripheral lung tissue in patients with interstitial lung disease ILD and the control group without ILD. values for the lobebased parameter $r S U V_{\max }$ was significantly higher in patients with ILD compared to the control group $(p<0.001)$. Lines indicate median values, boxes indicate the values between the upper and the lower quartile, whiskers indicate $95 \%$ confidence interval, and dots indicate outliers.

the correlation between $\mathrm{SUV}_{\max }, \mathrm{rSUV}_{\max }$, and the gold standard (regional radiological signs for ILD by CT) were performed using receiver operating characteristic (ROC) and area under the curve (AUC) analyses. For ROC analyses, the calculated AUC for $\mathrm{rSUV}_{\max }$ was 0.70 (95\% confidence interval=0.61-0.79), while that for $\mathrm{SUV}_{\max }$ was $0.57(95 \%$ confidence interval $=0.47-0.67$; Figure 3 ), indicating that there is a stronger correlation between the parameter $\mathrm{rSUV}_{\max }$ and the above-mentioned gold standard (regional radiological signs for ILD by CT), compared to the correlation between $\mathrm{SUV}_{\max }$ and the gold standard.

\section{Discussion}

Comparing FDG uptake in patients with LC between patients in the ILD group and those in the control group, we found significantly higher values for $\mathrm{SUV}_{\max }$ in patients with ILD, confirming the hypothesis of this study that an increased FDG uptake in peripheral lung tissue can be used as an imaging surrogate for the differentiation between patients with surgerytriggered progression of pre-existing ILD and those that do not have an increased risk for ILD. ROC analyses revealed a higher correlation between $\mathrm{rSUV}_{\max }$ and the presence of ILD as compared to the gold standard $\mathrm{SUV}_{\max }$.

In clinical routine, the introduction of a threshold value for the differentiation between patients with and without ILD could potentially help to identify those patients that have an increased risk for the onset or progression of ILD. This information could help to identify patients with increased risk

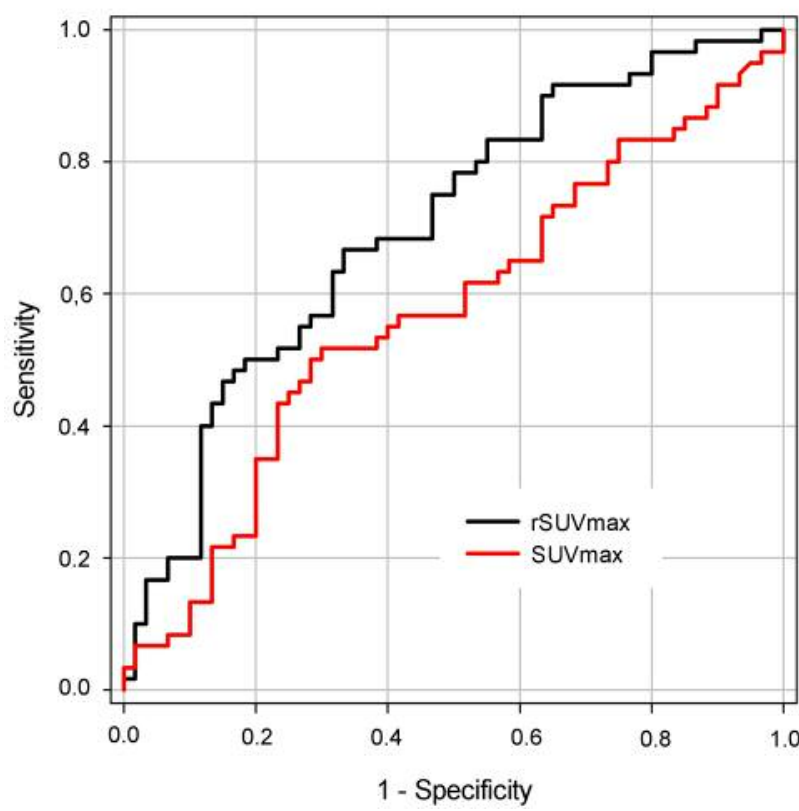

Figure 3. Area under the curve (AUC) analysis for maximum standardized uptake value $\left(S U V_{\max }\right)$ and relative maximum standardized uptake value $\left(r S U V_{\max }\right)$. Receiver operating characteristic analysis comparing the $S U V_{\text {max }}$ and $r S U V_{\text {max }}$ in patients with and without interstitial lung disease gave an AUC for $r S U V_{\text {max }}$ of 0.70 (95\% confidence interval=0.61-0.79), and 0.57 (95\% confidence interval $=0.47-0.67)$ for $S U V_{\max }$.

for progressive ILD after lung surgery, thereby influencing clinical decision-making for therapy stratification, especially in those patients with impaired lung function. In particular, patients at high risk for ILD could potentially benefit more when stratified to a non-invasive therapeutic procedure, since surgery is known to be a trigger for the exacerbation of ILD, such as IPF (15-19). If necessary, patients at high risk for progressive ILD might be treated with additional medication in order to prevent further progression of ILD, even in cases lacking or showing few signs of ILD in CT (27). In a second step, it would be of interest to compare overall survival of patients with LC at high risk for progression of pre-existing ILD that undergo non-surgical therapy with those treated with surgical therapy in order to ensure that high-risk patients have benefits when stratified for non-invasive care. Importantly, the acquisition of this information does not significantly affect the workload of the department, since patients with LC are routinely managed with ${ }^{18} \mathrm{~F}-\mathrm{FDG}-\mathrm{PET} / \mathrm{CT}$, and semiautomated $\mathrm{SUV}_{\max }$ and $\mathrm{rSUV}_{\max }$ measurements in the lung periphery can be derived within less than 10 minutes for each patient, as stated in the present study.

Results from the present pilot study are supportive of findings published in previous articles that demonstrated increased FDG uptake in the lung parenchyma of patients 
with IPF (10-13). As stated by Win et al., ${ }^{18}$ F-FDG-PET seems to have an even higher sensitivity for the detection of early pulmonary diseases in IPF as compared to HRCT (10). Nevertheless, the underlying pathogenesis of IPF (28-31), as well as the pathophysiological process that is responsible for the increased FDG uptake even in lung areas with normal HRCT signs are not yet understood (10). According to these authors, the presence of diffusely increased pulmonary $\mathrm{SUV}_{\text {max }}$ implies that increased FDG uptake is not predominantly caused by the colonization of infiltrates following infection due to dilated airways (10). Nevertheless, ${ }^{18}$ F-FDG-PET has been introduced as a surrogate endpoint for clinical trials evaluating the therapeutic benefit of newly introduced drugs against IPF (10). In diseases other than IPF, ${ }^{18} \mathrm{~F}-\mathrm{FDG}$-PET/CT is already used as an imaging surrogate for therapy response, as for example in patients suffering from lymphoma, when using the well-established Deauville score (32-38).

Our study has some limitations. One is its retrospective design with the relatively small number of 20 patients included in this pilot study. Secondly, in some patients lacking preoperative inspiratory CT, ILD was quantified using low-dose CT accompanying the PET scan. These CT scans were performed in respiratory center position, which weakens the CT-based diagnosis of ILD. In order to address this limitation, an identical number of patients also lacking initial inspiratory CT were included in the ILD and the control groups. In addition, postoperative CT scans were performed as part of oncological aftercare using contrast agent, which is not the clinical standard for the interpretation of interstitial lung diseases when performing dedicated CT scans for ILD imaging. In addition, in larger prospective studies, the clinical impact of $\mathrm{SUV}_{\max }$-and $\mathrm{rSUV}_{\max }$-based ILD analysis on overall survival could be compared, especially when stratifying high-risk patients for non-surgical treatment, and those with lower or moderate risk for surgery.

In conclusion, patients with LC scheduled for surgical treatment with pre-existing ILD presented significantly higher $\mathrm{rSUV}_{\max }$ in ${ }^{18} \mathrm{~F}$-FDG-PET/CT compared to patients of the control group, leading to us to propose $\mathrm{rSUV}_{\max }$ as a valuable imaging surrogate for the detection of progressive ILD in postoperative follow-up. Since surgery is a possible trigger for the exacerbation of IPF, the identification of patients with increased $\mathrm{rSUV}_{\max }$ could lead to their stratification as being at high risk for progressive ILD, and to their potential exclusion from surgical resection, or administration of supportive medication when available. Nevertheless, the introduction of dedicated $\mathrm{rSUV}_{\text {max }}$-based thresholds for the differentiation of high-risk patients from those with lower or moderate risk should be performed in prospective studies with larger numbers of patients.

\section{References}

1 Putman RK, Hatabu H, Araki T, Gudmundsson G, Gao W, Nishino M, Okajima Y, Dupuis J, Latourelle JC, Cho MH, ElChemaly S, Coxson HO, Celli BR, Fernandez IE, Zazueta OE, Ross JC, Harmouche R, Estépar RS, Diaz AA, Sigurdsson S, Gudmundsson EF, Eiríksdottír G, Aspelund T, Budoff MJ, Kinney GL, Hokanson JE, Williams MC, Murchison JT, MacNee W, Hoffmann U, O’Donnell CJ, Launer LJ, Harrris TB, Gudnason V, Silverman EK, O'Connor GT, Washko GR, Rosas IO and Hunninghake GM: Association between interstitial lung abnormalities and all-cause mortality. JAMA 315: 672-681, 2016.

2 Axelsson GT, Putman RK, Araki T, Sigurdsson S, Gudmundsson EF, Eiriksdottir G, Aspelund T, Miller ER, Launer LJ, Harris TB, Hatabu H, Gudnason V, Hunninghake GM and Gudmundsson G: Interstitial lung abnormalities and self-reported health and functional status. Thorax, 2018. doi: 10.1136/thoraxjnl-2017210956. [Epub ahead of print]

3 Araki T, Putman RK, Hatabu H, Gao W, Dupuis J, Latourelle JC, Nishino M, Zazueta OE, Kurugol S, Ross JC, San José Estépar R, Schwartz DA, Rosas IO, Washko GR, O'Connor GT and Hunninghake GM: Development and progression of interstitial lung abnormalities in the Framingham Heart Study. Am J Respir Crit Care Med 194: 1514-1522, 2016.

4 Marshall DC, Salciccioli JD, Shea BS and Akuthota P: Trends in mortality from idiopathic pulmonary fibrosis in the European Union: an observational study of the WHO mortality database from 20012013. Eur Respir J, 2018. doi: 10.1183/ 13993003.01603-2017.

5 Collard HR, Ward AJ, Lanes S, Cortney Hayflinger D, Rosenberg DM and Hunsche E: Burden of illness in idiopathic pulmonary fibrosis. J Med Econ 15: 829-835, 2012.

6 Oda K, Yatera K, Fujino Y, Kido T, Hanaka T, Sennari K, Fushimi K, Matsuda S and Mukae H: Respiratory comorbidities and risk of mortality in hospitalized patients with idiopathic pulmonary fibrosis. Respir Investig 56: 64-71, 2018.

7 Hubbard R, Venn A, Lewis S and Britton J: Lung cancer and cryptogenic fibrosing alveolitis. A population-based cohort study. Am J Respir Crit Care Med 161: 5-8, 2000.

8 Le Jeune I, Gribbin J, West J, Smith C, Cullinan P and Hubbard $\mathrm{R}$ : The incidence of cancer in patients with idiopathic pulmonary fibrosis and sarcoidosis in the UK: Respir Med 101: 2534-2540, 2007.

9 Kreuter M, Ehlers-Tenenbaum S and Schaaf M, Oltmanns U, Palmowski K, Hoffmann H, Schnabel PA, Heußel CP, Puderbach M, Herth FJ and Warth A: Treatment and outcome of lung cancer in idiopathic interstitial pneumonias. Sarcoidosis Vasc Diffuse Lung Dis 31: 266-274, 2015.

10 Win T, Thomas BA, Lambrou T, Hutton BF, Screaton NJ, Porter JC, Maher TM, Endozo R, Shortman RI, Afaq A, Lukey P, Ell PJ and Groves AM: Areas of normal pulmonary parenchyma on HRCT exhibit increased FDG PET signal in IPF patients. Eur J Nucl Med Mol Imaging 41: 337-342, 2014.

11 Lee EY, Wong CS, Fung SL, Yan PK and Ho JC: SUV as an adjunct in evaluating disease activity in idiopathic pulmonary fibrosis - a pilot study. Nucl Med Commun 35: 631-637, 2014.

12 Umeda Y, Demura Y, Morikawa M, Anzai M, Kadowaki M, Ameshima S, Tsuchida T, Tsujikawa T, Kiyono Y, Okazawa H, Ishizaki T and Ishizuka T: Prognostic value of dual-time-point ${ }^{18}$ F-FDG PET for idiopathic pulmonary fibrosis. J Nucl Med 56 : 1869-1875, 2015. 
13 Jacquelin V, Mekinian A, Brillet PY, Nunes H, Fain O, Valeyre $\mathrm{D}$ and Soussan M: FDG-PET/CT in the prediction of pulmonary function improvement in nonspecific interstitial pneumonia. A Pilot Study. Eur J Radiol 85: 2200-2205, 2016.

14 Kratochwil C, Haberkorn U and Giesel FL: PET/CT for diagnostics and therapy stratification of lung cancer. Der Radiologe 50: 684-691, 2010.

15 Sakamoto S, Homma S, Kawabata M, Kono T, Seki K, Nakata $\mathrm{K}$ and Yoshimura K: Fatal acute exacerbation of idiopathic pulmonary fibrosis/usual interstitial pneumonia initially in the right lung after surgery lobectomy for left lung cancer. Nihon Kokyuki Gakkai Zasshi 42: 760-766, 2004.

16 Kushibe K, Kawaguchi T, Takahama M, Kimura M, Tojo T and Taniguchi S: Operative indications for lung cancer with idiopathic pulmonary fibrosis. Thorac Cardiovasc Surg 55: 505508, 2007.

17 Hoshikawa Y and Kondo T: Perioperative lung injury: acute exacerbation of idiopathic pulmonary fibrosis and acute interstitial pneumonia after pulmonary resection. Nihon Geka Gakkai Zasshi 105: 757-762, 2004.

18 Yuksel M, Ozyurtkan MO, Bostanci K, Ahiskali R and Kodalli $\mathrm{N}$ : Acute exacerbation of interstitial fibrosis after pulmonary resection. Ann Thorac Surg 82: 336-338, 2006.

19 Fujimoto T, Okazaki T, Matsukura T, Hanawa T, Yamashita N, Nishimura K, Kuwabara M and Matsubara Y: Operation for lung cancer in patients with idiopathic pulmonary fibrosis: Surgical contraindication? Ann Thorac Surg 76: 1674-1678, 2003.

20 Flechsig P, Kratochwil C, Schwartz LH, Rath D, Moltz J, Antoch G, Heussel CP, Rieser M, Warth A, Zabeck H, Kauczor HU, Haberkorn U and Giesel FL: Quantitative volumetric CThistogram analysis in N-staging of $18 \mathrm{~F}-\mathrm{FDG}$-equivocal patients with lung cancer. J Nucl Med 55: 559-564, 2014.

21 Giesel FL, Schneider F, Kratochwil C, Rath D1, Moltz J, Holland-Letz T, Kauczor HU, Schwartz LH, Haberkorn U and Flechsig P: Correlation between $\mathrm{SUV}_{\max }$ and $\mathrm{CT}$ radiomic analysis using lymph node density in PET/CT-based lymph node staging. J Nucl Med 58: 282-287, 2017.

22 Giesel F, Will L, Lawal I, Lengana T, Kratochwil C, Vorster M, Neels O, Reyneke F, Haberkon U, Kopka K and Sathekge M: Intra-individual comparison of (18)F-PSMA-1007 and (18)FDCFPyL PET/CT in the prospective evaluation of patients with newly diagnosed prostate carcinoma: A pilot study. J Nucl Med, 2017. doi: 10.2967/jnumed.117.204669. [Epub ahead of print]

23 Best AC, Meng J, Lynch AM, Bozic CM, Miller D, Grunwald GK and Lynch DA: Idiopathic pulmonary fibrosis: physiologic tests, quantitative CT indexes, and CT visual scores as predictors of mortality. Radiology 246: 935-940, 2008.

24 Hansell DM, Goldin JG, King TE, Jr., Lynch DA, Richeldi L and Wells AU: CT staging and monitoring of fibrotic interstitial lung diseases in clinical practice and treatment trials: a position paper from the Fleischner Society. Lancet Respir Med 3: 483-496, 2015.

25 Lynch DA, Godwin JD, Safrin S, Starko KM, Hormel P, Brown KK, Raghu G, King TE Jr., Bradford WZ, Schwartz DA and Richard Webb W: High-resolution computed tomography in idiopathic pulmonary fibrosis: Diagnosis and prognosis. Am J Respir Crit Care Med 172: 488-493, 2005.

26 Jacob J, Bartholmai BJ, Rajagopalan S, Brun AL, Egashira R, Karwoski R, Kokosi M, Wells AU and Hansell DM: Evaluation of computer-based computer tomography stratification against outcome models in connective tissue disease-related interstitial lung disease: A patient outcome study. BMC Med 14: 190, 2016.

27 Iwata T, Yoshida S, Nagato K, Nakajima T, Suzuki H, Tagawa T, Mizobuchi T, Ota S, Nakatani Y and Yoshino I: Experience with perioperative pirfenidone for lung cancer surgery in patients with idiopathic pulmonary fibrosis. BMC Med 45: 1263-u70, 2015.

28 Coultas DB, Zumwalt RE, Black WC and Sobonya RE: The epidemiology of interstitial lung diseases. Am J Respir Crit Care Med 150: 967-972, 1994.

29 Raghu G, Weycker D, Edelsberg J, Bradford WZ and Oster G: Incidence and prevalence of idiopathic pulmonary fibrosis. Am J Respir Crit Care Med 174: 810-816, 2006.

30 Gross TJ and Hunninghake GW: Idiopathic pulmonary fibrosis. N Engl J Med 345: 517-525, 2001.

31 Noth I and Martinez FJ: Recent advances in idiopathic pulmonary fibrosis. Chest 132: 637-650, 2007.

32 Follows GA, Ardeshna KM, Barrington SF, Culligan DJ, Hoskin PJ, Linch D, Sadullah S, Williams MV, Wimperis JZ: Guidelines for the first line management of classical Hodgkin lymphoma. Br J Haematol 166: 34-49, 2014.

33 Barrington SF and Kluge R: FDG PET for therapy monitoring in Hodgkin and non-Hodgkin lymphomas. Eur J Nucl Med Mol Imaging 44: 97-110, 2017.

34 Fallanca F, Alongi P, Incerti E, Gianolli L, Picchio M, Kayani I and Bomanji J: Diagnostic accuracy of FDG PET/CT for clinical evaluation at the end of treatment of HL and NHL: A comparison of the Deauville Criteria (DC) and the International Harmonization Project Criteria (IHPC). Eur J Nucl Med Mol Imaging 43: 1837-1348, 2016.

35 Barrington SF, Qian W, Somer EJ, Franceschetto A, Bagni B, Brun E, Almquist H, Loft A, Højgaard L, Federico M, Gallamini A, Smith P, Johnson P, Radford J and O'Doherty MJ: Concordance between four European centres of PET reporting criteria designed for use in multicentre trials in Hodgkin lymphoma. Eur J Nucl Med Mol Imaging 37: 1824-1833, 2010.

36 Furth C, Meseck RM, Steffen IG, Schoenberger S, Denecke T, Henze G, Hautzel H, Hofheinz F, Großer O, Hundsdoerfer P, Amthauer $\mathrm{H}$ and Ruf J: SUV-measurements and patient-specific corrections in pediatric Hodgkin-lymphoma: Is there a benefit for PPV in early response assessment by FDG-PET? Pediatr Blood Cancer 59: 475-480, 2012.

37 Biggi A, Gallamini A, Chauvie S, Hutchings M, Kostakoglu L, Gregianin M, Meignan M, Malkowski B, Hofman MS and Barrington SF: International validation study for interim PET in ABVD-treated, advanced-stage Hodgkin lymphoma: interpretation criteria and concordance rate among reviewers. J Nucl Med 54: 683-690, 2013.

38 Le Roux PY, Gastinne T, Le Gouill S, Nowak E, Bodet-Milin C and Querellou S, Mahe B, Dubruille V, Blin N, Salaun PY and Bodere-Kraeber F: Prognostic value of interim FDG PET/CT in Hodgkin's lymphoma patients treated with interim responseadapted strategy: comparison of International Harmonization Project (IHP), Gallamini and London criteria. Eur J Nucl Med Mol Imaging 38: 1064-1071, 2011.

Received June 11, 2018

Revised June 25, 2018

Accepted June 28, 2018 